\title{
Antioxidant and antimicrobial effects of polyoxometalates.
}

\author{
Farzana $R^{*}$, Iqra P, Hunaiza T \\ Department of Zoology, Faculty of Natural Sciences, Lahore College for Women University, Lahore, Pakistan
}

\begin{abstract}
Drug resistance among pathogenic bacteria leads to the worldwide prevalence of nosocomial and community infections. Polyoxometalates (POMs) are one of the novel therapeutic agents that are tested against microbes. The aim of present study is to investigate the antimicrobial and antioxidant activity of synthetic Polyoxometalates i.e. (irono-substituted phosphotungstate, Cesium phosphotungstate, Silicovanadate) and their synergistic effect with $\beta$-lactam antibiotics against some Methicillin resistant Staphylococcus aureus (MRSA). The collected strains were cultured on different enriched and selective media and identified by their physical and morphological characteristics. The antimicrobial activity of POMs was determined by using their different concentrations including $5 \mathrm{mg} / \mathrm{ml}, 10 \mathrm{mg} / \mathrm{ml}$, $15 \mathrm{mg} / \mathrm{ml}$ and $20 \mathrm{mg} / \mathrm{ml}$, with $\beta$-lactam antibiotics (Ciprofloxacin and Imipenem). The Minimum inhibitory concentration (MIC) was calculated through standard agar dilution method. The

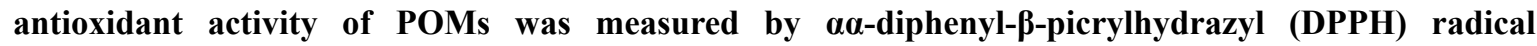
scavenging activity. The results revealed that antibacterial activity of irono-substitued phosphotungstate $(19 \mathrm{~mm})$ was more than that of other POMs used. Highest zones were obtained at 20mg/ml concentration of POMs used and MIC was calculated to be $5 \mathrm{mg} / \mathrm{ml}$. Silicovanadate was observed to be more antioxidant as compared to other POMs. POMs possess strong antibacterial and antioxidant activity and can be used in conjugation with other $\beta$-lactam antibiotics as they possess synergistic effect with them.
\end{abstract}

Keywords: Polyoxometalates, Antibacterial, Antibiotics, Antioxidant.

Accepted on January 16, 2018

\section{Introduction}

During last two decades the frequency and types of life threatening fungal and bacterial infections has increased dramatically. This has been as a result of change in both medical practice and in the disease to which humans are exposed [1]. Antimicrobial drug resistance is a worldwide problem in both developing and developed countries [2]. The increase in resistance of Gram-negative is faster than Grampositive bacteria and there are fewer new and developmental antibiotics active against Gram negative bacteria. Drug development programs seem insufficient to provide therapeutic cover in 10-20 years [3]. Methicillin resistant Staphylococcus aureus (MRSA) and vancomycin-resistant enterococci (VRE) are of particular concern. In the United States, approximately $60 \%$ of staphylococcal infections in the intensive care unit are now caused by MRSA, and percentages continue to rise [4]. MRSA has been pandemic for over a decade and is causing a major serious increase in serious staphylococcal infections. It is a variety of Staphylococcus aureus (SA) which exists on the skin and nose of about $30 \%$ of the population without causing any serious health effects but can cause wound infections and severe bloodstream infections [5]. Polyoxometalates (PMs) as discrete metal-oxide cluster anions with high solubility in water and photochemically and electrochemically active property have a wide range of structures not only in molecular size from sub-nano to sub-micrometers with a various combination of metals but also in symmetry and highly negative charge. One of the reasons for such a structural variety originates from their conformation change (due to the condensed aggregation and the structural assembly) which strongly depends on environmental parameters such as solution $\mathrm{pH}$, concentration, and coexistent foreign inorganic and/or organic substances. POMs are immensely used as anti-tumor, antiviral and antibacterial agents in the field of medicine due to their unique physicochemical properties. Several PMs have been licensed toward the chemotherapy of solid tumors (such as human gastric cancer and pancreatic cancer), DNA and RNA viruses (such as HIV, influenza, and SARS), and drug resistant bacteria such as MRSA and VRSA [6].

By keeping all the effective perspectives of POMs under consideration, the present research was designed to analyze the antimicrobial activity of POMs and its combined effect with antibiotic against MRSA strains and to evaluate the antioxidant activity of POMs.

\section{Materials and Methods}

\section{Bacterial strains and chemicals}

20 bacterial strains used were collected from Post Graduate Medical Institute (PGMI). All Methicillin resistant Staphylococcus aureus (MRSA) strains were collected from samples of different pat ients and were identified on the basis of biochemical test. Antibiotic discs (BioAnase) Imipenem (10 $\mu \mathrm{g})$ and Amoxicillin $(10 \mu \mathrm{g})$ were used in this study.

All POMs were synthesized by the courtesy of COMSATS institute of information technology. 


\section{Susceptibility check of MRSA strains}

Before checking antibacterial activity of POMs, there was needed to confirm that these strains were beta lactam antibiotic resistant. The prepared Nutrient and Muller-Hinton agar media was inoculated with $24 \mathrm{~h}$ cultures of test strains and poured into relabeled sterilized petri plates. After solidification the standard discs Imipenem and Amoxicillin (10 $\mu \mathrm{g} / \mathrm{disc})$ and a filter paper discs were placed on plates. After incubation at $37^{\circ} \mathrm{C}$ for $24 \mathrm{~h}$ it was observed that strains were resistive to Amoxicillin as there was no zone of inhibition around the antibiotic disc and sensitive to Imipenem as there was clear zone of inhibition around the antibiotic disc.

\section{Antibacterial activity of POMs by disc diffusion assay}

Kirby's disc diffusion method was followed to test the antibacterial activity of polyoxometalates against MRSA. The prepared Nutrient and Muller-Hinton agar medium was poured into pre-labeled sterilized petri plates. A single colony of test organism was grown overnight in Nutrient broth medium on rotatory shaker $(200 \mathrm{rpm})$ at 35 . The freshly prepared culture $700 \mu \mathrm{l}$ of water and $200 \mu \mathrm{l}$ of culture was taken through a micro pipette and dissolved. This diluted culture was swabbed on solidified agar plates.

Sterile filter paper disks of Whatmann filter, $5 \mathrm{~mm}$ in diameter were used for disk diffusion assay. These blank discs impregnated with $5 \mathrm{mg} / \mathrm{ml}, 10 \mathrm{mg} / \mathrm{ml}$ and $15 \mathrm{mg} / \mathrm{ml}$ of compound (silicovanadate, irono-substituted phosphotungstate, cesium phosphotungstate) were diffused. Standard disc of imipenem $(10 \mu \mathrm{g} /$ disc $)$ and amoxicillin $(10 \mu \mathrm{g})$ and a blank disc (impregnated with water) were used as positive and negative control, respectively. This test was performed for MRSA. After discs were diffused all plates were kept in inverted position in incubator at $37^{\circ} \mathrm{C}$ for $18-24 \mathrm{~h}$. The diameters of zones of inhibition were measured in millimeters. The antibacterial activity of silicovanadate was compared with another compound (ironosubstituted with DMSO) negative control and imipenem and amoxicillin $(10 \mu \mathrm{g} / \mathrm{disc})$ as positive control. Antibacterial activity is shown in Table 1.

Table 1. Antibacterial activity POMs with Imipenem and amoxicillin at different concentration. *All values are given as Mean \pm S.D.

\begin{tabular}{|c|c|c|c|c|c|c|c|c|c|c|c|c|}
\hline \multirow{3}{*}{$\begin{array}{l}\text { Sr. } \\
\text { No. }\end{array}$} & \multicolumn{6}{|c|}{ COMPOUND WITH IMIPENEM } & \multicolumn{6}{|c|}{ COMPOUND WITH AMOXCILLIN } \\
\hline & \multicolumn{2}{|c|}{$\begin{array}{l}\text { Ironosubstituted } \\
\text { phosphotungstate }\end{array}$} & \multicolumn{2}{|c|}{$\begin{array}{l}\text { Cesium } \\
\text { phosphotungstate }\end{array}$} & \multicolumn{2}{|c|}{ Silicovanadate } & \multicolumn{2}{|c|}{$\begin{array}{l}\text { Ironosubstituted } \\
\text { phosphotungstate }\end{array}$} & \multicolumn{2}{|c|}{$\begin{array}{l}\text { Cesium } \\
\text { phosphotungstate }\end{array}$} & \multicolumn{2}{|c|}{ Silicovanadate } \\
\hline & $\begin{array}{l}\text { Conc. } \\
\mathrm{mg} / \mathrm{ml}\end{array}$ & $\begin{array}{l}\text { Zone of } \\
\text { inhibition }\end{array}$ & $\begin{array}{l}\text { Conc. } \\
\mathrm{mg} / \mathrm{ml}\end{array}$ & $\begin{array}{l}\text { Zone of } \\
\text { inhibition }\end{array}$ & $\begin{array}{l}\text { Conc. } \\
\mathrm{mg} / \mathrm{ml}\end{array}$ & $\begin{array}{l}\text { Zone of } \\
\text { inhibition }\end{array}$ & $\begin{array}{l}\text { Conc. } \\
\mathrm{mg} / \mathrm{ml}\end{array}$ & $\begin{array}{l}\text { Zone of } \\
\text { inhibition }\end{array}$ & $\begin{array}{l}\text { Conc. } \\
\mathrm{mg} / \mathrm{ml}\end{array}$ & $\begin{array}{l}\text { Zone of } \\
\text { inhibition }\end{array}$ & $\begin{array}{l}\text { Conc. } \\
\mathrm{mg} / \mathrm{ml}\end{array}$ & $\begin{array}{l}\text { Zone of } \\
\text { inhibition }\end{array}$ \\
\hline 1 & 5 & $9 \pm 0.76 \mathrm{~mm}$ & 5 & No zone & 5 & No zone & 5 & $7 \pm 2.5 \mathrm{~mm}$ & 5 & No zone & 5 & No zone \\
\hline 2 & 10 & $14 \pm 0.30 \mathrm{~mm}$ & 10 & No zone & 10 & No zone & 10 & $12 \pm 0.57 \mathrm{~mm}$ & 10 & No zone & 10 & No zone \\
\hline 3 & 15 & $18 \pm 1.0 \mathrm{~mm}$ & 15 & No zone & 15 & No zone & 15 & $16 \pm 1.0 \mathrm{~mm}$ & 15 & No zone & 15 & No zone \\
\hline 4 & 20 & $19 \pm 1.5 \mathrm{~mm}$ & 20 & No zone & 20 & No zone & 20 & $18 \pm 1.7 \mathrm{~mm}$ & 20 & No zone & 20 & No zone \\
\hline
\end{tabular}

\section{Determination of minimum inhibitory concentration}

MIC is lowest concentration that prevents the visible growth of bacteria. Standard agar dilution method was used for estimation of MIC [7]. The optical density (OD) of bacterial suspension was maintained at $0.8^{-1}$. Bacterial suspension having $10^{5}$ colony forming unit (CFU) $\mathrm{ml}^{-1}$ was added to each Muller Hinton agar plate containing different concentration of POMs and the growth of the bacteria was evaluated after $24 \mathrm{~h}$ incubation at $37^{\circ} \mathrm{C}$. Serial dilutions were prepared with concentration ranging from 5 to $20 \mathrm{mg} / \mathrm{ml}$. The MIC values were interpreted as highest dilution (lowest concentration) of sample, which showed clear zone. All tests were performed in triplicates.

\section{Antioxidant activity of POMs}

Free radical scavenging activity was evaluated using Lascorbic acid as standard antioxidant. The radical scavenging activity was measured using stable radical, DPPH according to method described by Chan et al. with some modified cations
[8]. All readings were compared with standard ascorbic acid $(55 \pm 0.001)$. Tests were carried out in triplicates.

\section{Calculation}

$\%$ scavenging activity

$=\frac{\text { (Absorbance of control }- \text { Absorbance of sample })}{\text { Absorbance of control }} \times 100$

Where:

Absorbance of control reaction=Absorbance of ascorbic acid

Absorbance of sample $=$ Absorbance of tested compound i.e. (POMs). All tests were carried out in triplicates.

\section{Statistical analysis}

Statistical analysis of results was done by SPSS 13.0 version. Values were recorded as mean and standard deviation as shown in Table 2. Statistical difference between means was 
determined by ANOVA followed by Post hoc Test $\mathrm{p} \leq 0.05$ was accepted as significant level.

Table 2. Comparison of POMs by One way ANOVA.

\begin{tabular}{|c|c|c|c|c|c|c|c|c|}
\hline \multirow{2}{*}{ Sr. No } & \multirow{2}{*}{$\mathbf{N}$} & \multirow{2}{*}{ Mean } & \multirow{2}{*}{ Std. deviation } & \multirow{2}{*}{ Std. Error } & \multicolumn{2}{|c|}{ 95\% Confidence Interval for mean } & \multirow[t]{2}{*}{ Minimum } & \multirow{2}{*}{ Maximum } \\
\hline & & & & & Lower Bound & Upper Bound & & \\
\hline 1 & 3 & 5 & 1 & 0.57735 & 2.5159 & 7.4841 & 4 & 6 \\
\hline 2 & 3 & 10 & 1 & 0.57735 & 7.5159 & 12.4841 & 9 & 11 \\
\hline 3 & 3 & 15 & 1 & 0.57735 & 12.5159 & 17.4841 & 14 & 16 \\
\hline 4 & 3 & 17 & 1 & 0.57735 & 14.5159 & 19.4841 & 16 & 18 \\
\hline 5 & 3 & 0 & 0 & 0 & 0 & 0 & 0 & 0 \\
\hline 6 & 3 & 0 & 0 & 0 & 0 & 0 & 0 & 0 \\
\hline 7 & 3 & 0 & 0 & 0 & 0 & 0 & 0 & 0 \\
\hline 8 & 3 & 0 & 0 & 0 & 0 & 0 & 0 & 0 \\
\hline 9 & 4 & 0 & 0 & 0 & 0 & 0 & 0 & 0 \\
\hline 10 & 3 & 0 & 0 & 0 & 0 & 0 & 0 & 0 \\
\hline 11 & 3 & 0 & 0 & 0 & 0 & 0 & 0 & 0 \\
\hline 12 & 3 & 0 & 0 & 0 & 0 & 0 & 0 & 0 \\
\hline Total & 37 & 3.8108 & 6.20859 & 1.02069 & 1.7408 & 5.8809 & 0 & 18 \\
\hline
\end{tabular}

\section{Results}

\section{Antibacterial susceptibility test}

Antibacterial activity of compounds were compared with each other and the zones of inhibition measured for this test showed that the values obtained for the irono-substituted phosphotungstate were highly significant than the two others. The zone of inhibition formed by all three compounds is shown in Figure 1 indicating as the highest zone of inhibition was obtained in irono-substituted phosphotungstate against MRSA at the maximum concentration of $20 \mathrm{mg} / \mathrm{ml}$. Moreover, synergistic effect of Imipenem and Amoxicillin was observed with irono-substituted phosphotungstate.
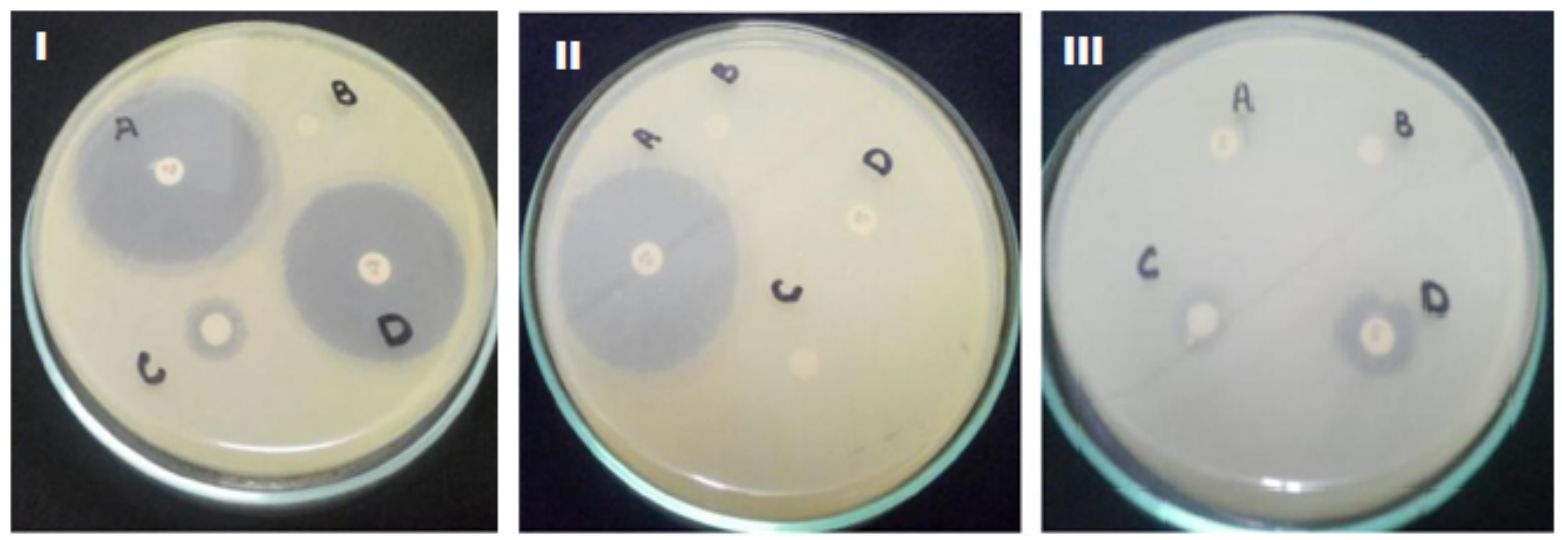

Figure 1. Antibacterial activity of synergistic effect of POMs with Imipenem and Amoxicillin at maximum concentration of $20 \mathrm{mg} / \mathrm{ml}$; [I] Antimicrobial activity of Ironosubstituted Phosphotungstate against MRSA; [II] Antimicrobial activity of Cesium Phosphotungstate against MRSA; [III]Antimicrobial activity of Silicovanadate against MRSA; A: Positive Control (Antibiotic Disc), B: Negative Control (Water), C: Compound, D: Compound+Antibiotic Disc.

\section{Antioxidant activity of POMs}

All POMs were evaluated for their free radical scavenging activity using DPPH assay. Reduction of DPPH can be observed by the decrease in the absorbance at $517 \mathrm{~nm}$. The result of DPPH activity is exhibited in Figure 2. The antioxidant activity of compounds was measured by spectrophotometer at different concentrations $(5 \mathrm{mg} / \mathrm{ml}, 10$ $\mathrm{mg} / \mathrm{ml}, 15 \mathrm{mg} / \mathrm{ml}$, and $20 \mathrm{mg} / \mathrm{ml})$. The DPPH ability of sample was reported as the 5 scavenging. Higher 5 of scavenging are correlated to higher antioxidant activity. The antioxidant activity present in the figure reveals that the antioxidant 
activity was increased as we increased the concentration of POMs. All the readings were compared with ascorbic acid (55 \pm 0.72 ) used as standard.

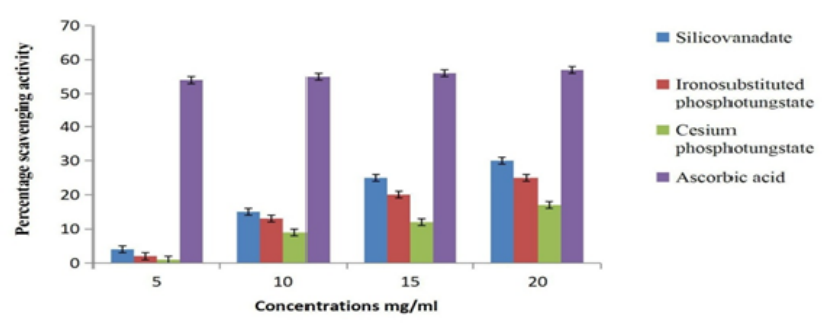

Figure 2. DPPH radical scavenging activity of different concentrations of Polyoxometalate

\section{Discussion}

The present study was designed to evaluate antibacterial effects of irono-substituted phosphotungstate, cesium phosphotungstate and silicovanadate against positive bacterial strain Methicillin resistant Staphylococcus aureus which was sensitive to one $\beta$-lactam antibiotic Imipenem and resistant to another (Amoxicillin). In our results iron substituted phosphotungstate showed antibacterial effects when checked individually but this effect was comparatively enhanced when it was regularly checked with beta-lactam antibiotics (synergistic effect). Staphylococcus aureus showed the highest sensitivity to this POM and was more adversely affected by irono-substituted phosphotungstate than the other two POMs. The highest inhibition zones were obtained at $20 \mathrm{mg} / \mathrm{ml}$ concentration of the POMs used. The antibacterial mechanism for POMs can be elucidated by the interaction of its charged ions and opposite charged microbial cell wall that leads to the leakage of intracellular constituents. The binding of charged ions with DNA and inhibition of mRNA synthesis occur via penetration of microorganisms and interfering with synthesis of mRNA and protein. A similar study that supports our result was conducted to analyze its inhibitory effects against pathogenic strains. In that study Tajima reported the effects of a mixture of tungstate and phosphate in in combination with beta-lactam antibiotics. He discovered that a factor (named "Factor $\mathrm{T}$ " for Tungstate) greatly enhanced the antibacterial effects of the drug in bacterial strains [9].

In another similar study by Pillai et al. supported our results where seven compounds named tetraryl-porphrins (two commercials and five synthetic) were checked for their antibacterial activity against one Gram positive strain and two gram negative strains. Among them gram negative $P$. aerugenosa was found to be more resistant one and $E$. coli was susceptible. Among all compounds one synthetic compound was found to be efficient against $P$. aerugenosa causing a reduction of survivors at a concentration of $8 \mu \mathrm{m}$ [10]. The antibacterial effect of the combination of various polyoxometalates with beta lactam antibiotics on MRSA strains is investigated by the use of both National Committee for Clinical Laboratory Standards (NCCLS) disk diffusion method and the agar dilution method. Keggin-structural polyoxotungstates and their lacunary species potentiated the antibacterial activity of beta-lactam antibiotics such as oxacillin, piperacillin and cefazolin on MRSA with high selectivity. The sodium Dodecyl sulfate polyacrylamide gel electrophoresis (SDS-PAGE) of the membrane proteins separated from MRSA revealed that polyoxotungstates depressed the formation of Penicillin-binding protein 2' (PBP2') and an enzyme that is essential for cell wall construction in the MRSA growth. It is concluded that polyoxotungstates make the MRSA strains susceptible to $\beta$ lactam antibiotics [6].

Apart antibacterial activity there is another feature that is antioxidant activity. Free radicals are involved in many disorders like neuro-degenerative disease, cancer and AIDS. Antioxidants through their scavenging power are useful for the management of those disorders. DPPH stable free radical method is an easy, rapid a sensitive way to survey the antioxidant activity of a specific compound [11]. Antioxidant activity of silicovanadate measured was greater than the other two POMS. Readings were taken and all these readings were compared with ascorbic acid $(55 \pm 0.72)$ used as standard. The absorption was increased by increasing the PR concentration. At a constant concentration level of $0.05 \%(\mathrm{w} / \mathrm{v}) \mathrm{CTAC}$ and $100 \mathrm{mgmL}-1$ of Mo, PR concentration in the range of $3.0 \times$ $10^{-6}-1.2 \times 10^{-4} \mathrm{~mol} \mathrm{~L}^{-1}$ of the ligand and contrary to the present study that after the particular concentration the absorbance remained approximately constant in recent studies of antioxidant activity of POMs (silicovanadate, irono substituted phosphotungstate and cesium phosphotungstate) was increased as we increased the concentration of compounds.

\section{Conclusion}

Based on results it can be interpreted that chemical compounds contain great amount of some important constituents (Tungstate) that have antimicrobial and antioxidant activity. So they can be used as effective agents for the treatment of several infectious diseases caused by bacteria and viruses as well, which are multi-resistant to a wide range of antibiotics. They also contain a remarkable amount of antioxidant agents which can prevent us from highly damaging free radicals or reactive oxygen species formed through various metabolic pathways running in our body. In this study all the three POMs were compared for their antimicrobial activity, irono-substituted phosphotungstate was more effective against gram positive bacterial growth because it can penetrate through the bacterial cell wall which consists of peptidoglycan and reach cytoplasmic membrane of bacteria. Other two compounds did not show any efficiency against bacterial growth. Silicovanadate was only effective at higher concentrations (25 $\mathrm{mg} / \mathrm{ml}$ ) but, the results showed that the values obtained for irono-substituted phophotungstate were highly significant $(\mathrm{p}<0.05)$.

\section{References}

1. Berman J, Sudbery PE. Canada abicans a molecular Revolution Built on Lessons from Staphylococcus cerevisiae. Nat Rev Genet. 2002;3:918-30

2. Tenover FC, Hughes. The challenges of emerging infectious diseases development and spread of multiple 
resistant bacterial pathogens. J Emerg Infect Dis. 1996;12:300-4.

3. Boucher HW, Talbot GH, Bradleg JS. An update from the infectious Diseases. Soc Am Clin Infect Dis. 2009;48:1-12.

4. Rice LB. Antimicrobial resistance in gram-positive bacteria. Am J Infect control. 2006;34:11-9.

5. Rhule JT, Hill CL, Judd DA, et al. Polyoxometalates in Medicine. J Coord Org Chem. 1998;98:327-57

6. Yamase T. Anti-tumor, anti-viral, and anti-bacterial activities of polyoxometalates for realizing an inorganic drug. J Mater Chem. 2005;15:4773-82.

7. Jones N, Ray B, Ranjit KT, et al. Antibacterial activity of $\mathrm{ZnO}$ nanoparticle suspensions on a broad spectrum of microorganisms. FEMS Fems Microbiol Lett. 2008;279:71-6.

8. Chan EWC, Lim YY, Chew YL. Antioxidant activity of Camellia sinensis leaves and tea from a lowland plantation in Malaysia. Food chem. 2007;102:1214-22.

9. Tajima Y. Purification of a factor that enhances the antibacterial activity of beta-lactams against methicillin- resistant Staphylococcus aureus: its identification as decaphosphotungstate. J Inorg Biochem. 1997;68:93-9.

10. Pillai SI, Subramanian SP, Kandaswamy M. Evaluation of antioxidant efficacy of vanadium-3-hydroxyflavone complex in streptozotocin-diabetic rats. $\mathrm{J}$ Chem-bio Interact. 2013;204:67-74.

11. Koleva II, VanBeek TA, Linssen JP, et al. Screening of plant extracts for antioxidant activity: a comparative study on three testing methods. Phytochem analysis. 2002;13:8-17.

\section{*Correspondence to}

Farzana Rashid

Associate Professor,

Lahore College for Women University, Lahore.

Tel: 0092-3077777730/3349957764

E-mail:dr.farzanarashid@gmail.com 